\title{
Management of Chronic Myeloid Leukemia with Sever COVID 19: A Case Report
}

\author{
Rasha I. Ibrahm*, Georgios P. Chatzis ${ }^{1}$, Mohamed A. Korayem², Mahmoud K. Mansour ${ }^{3}$ \\ ${ }^{1}$ Department of Internal Medicine, Clinical Hematology, Faculty of Medicine, Ain Shams University, Egypt; ${ }^{2}$ King Salman Specialist \\ Hospital, Hail, Kingdom of Saudi Arabia; ${ }^{3}$ Department of Microbiology, Faculty of medicine, Suez Canal University, Egypt
}

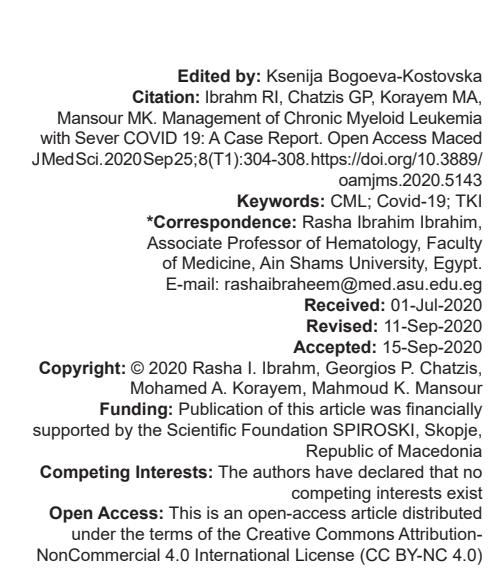

\section{Introduction}

Chronic myelogenous leukemia $(\mathrm{CML})$ is a myeloproliferative disorder characterized by increased proliferation of the granulocytic cell line without the loss of their capacity to differentiate. The peripheral blood shows an increased number of granulocytes and their immature precursors, including occasional blast cells.

CML is caused by a single, specific genetic mutation, known as the Philadelphia chromosome. CML progresses through three phases: Chronic, accelerated, and blast. CML accounts for $20 \%$ of all leukemia affecting adults. Historically, the median survival of patients with CML was 3-5 years from the time of diagnosis. At present, patients with CML have a median survival of 5 or more years. In fact, CML patients are currently approaching normal life expectancyas a result of the improvement of earlier diagnosis, improved therapy with target therapy, tyrosine kinase inhibitors (TKI).

The coronavirus pandemic, is an ongoing pandemic of coronavirus disease 2019 (COVID19), caused by severe acute respiratory syndrome coronavirus 2 (SARS-CoV-2). The outbreak was first identified in Wuhan, China, in December 2019. Cases presentation ranged from mild asymptomatic cases up to sever pneumonia, cytokine storm syndrome, and ARDS.

There are no available specific data on the COVID-19 in CML patients treated with (TKI).

At present, we have no evidence to suggest that chronic phase CML patients on TKI are at higher risk of contracting SARS-CoV-2 or having a more severe form of the viral infection compared to the general population.

In this case report, we will present how we managed a case of CML that presented with sever COVID 19 infection.

\section{Case Presentation}

A 57-year-old male patient with history of diabetes mellitus (DM) on metformin 850 mg twice daily, diagnosed as chronic phase CML 10 years ago and he was started and maintained on imatinib $400 \mathrm{mg}$ OD and achieved major molecular response (MMR). Last PCR for BCR-ABL 3 months ago 0.0001\%. 
He presented to Emergency Department (ED) May 19, 2020, in King Salman Specialist Hospital, Hail, Kingdom of Saudi Arabia, complaining of cough for 2 days, with fever, nausea no shortness of breath, no abdominal pain no vomiting, no diarrhea, no history of contact with positive case of COVID 19. On examination: He looks well, conscious, temperature was $38.4^{\circ} \mathrm{C}$, other vital data within normal, chest examination was normal, abdomen: Soft and lax. White blood cell 5.75 $\times 10^{6} / \mu \mathrm{L}$ absolute neutrophil count (ANC) $4.37 \times 10^{6} / \mu \mathrm{L}$ lymphocytes $1.1 \times 10^{6} / \mu \mathrm{L}$ hemoglobin $14.6 \mathrm{~g} / \mathrm{dL}$ platelet $220 \times 10^{9} / \mathrm{L}$, normal kidney and liver function tests, blood sugar $12 \mathrm{mmol}$, and normal chest X-ray (CXR).

COVID 19 swab taken and patient received paracetamol and antitussive, his medications of DM are modified, and advised for home isolation and to continue on imatinib $400 \mathrm{mg}$.

Two days later he returned to ED with complain of epigastric burning sensation, associated with loss of appetite, diarrhea for 1 day and productive cough.

Temperature was $37.5^{\circ} \mathrm{C}$, heart rate was $103 / \mathrm{min}$, oxygen saturation $\left(\mathrm{O}_{2}\right.$ Sat) $89 \%$ on room air, BP 160/90, chest examination: Equal bilateral air entry, and no adventitious sounds (Table 1).

He was admitted in isolation ward and he was started on hydroxyclorouquine, azithromycin, ceftriaxone, and prophylactic enoxaparin as per protocol. With ECG monitor of QT interval, and he continued on imatinib $400 \mathrm{mg}$ OD.

On $2^{\text {nd }}$ day of admission patient developed dyspnea his temperature increased to $39^{\circ} \mathrm{C}, \mathrm{O}_{2}$ sat $88 \%$ on $5 \mathrm{~L} / \mathrm{min}$ nasal cannula. Chest exam showed bilateral crepitations, CXR: Bilateral infiltrations.

Patient shifted to ICU for close monitoring and we continued on imatinib $400 \mathrm{mg}$ daily as no drug interaction with his medications and normal ANC, platelet, and liver function tests (Table 2, Figure 1).

Patient stayed in ICU for 2 days with stable condition, but with fluctuation of temperature, and $\mathrm{O}_{2}$ Sat.

On $3^{\text {rd }}$ day of ICU admission, his $\mathrm{O}_{2}$ Sat markedly deteriorated.

Patient was sedated, intubated and kept on mechanical ventilation AC (MODE) VT, 440. RR, 20. PEEP, 10. $\mathrm{FIO}_{2}, 50 \%$.

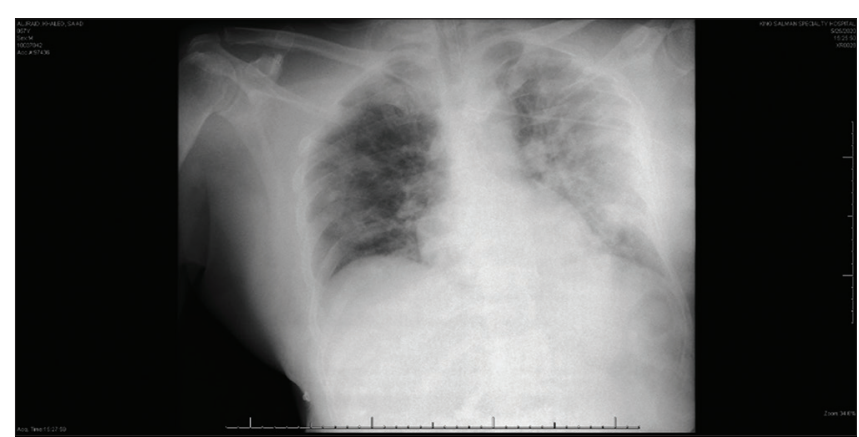

Figure 1: Chest $X$-ray of patient on day of admission to ICU
We started patient on following medications based on local COVID-19 management protocol: Therapeutic dose of anticoagulation of enoxaparin $1 \mathrm{mg} / \mathrm{kg} / \mathrm{BID} \mathrm{SC}$, as D-DIMER more than 1 and he has severe COVID 19 pneumonia.

Methylprednisolone $40 \mathrm{mg}$ IV $\mathrm{q} 12 \mathrm{~h}$, lopinavir/ritonavir $400 / 100 \mathrm{mg}$ q12h oral for 14 days, ribavirin $400 \mathrm{mg} \mathrm{q} 12 \mathrm{~h}$ oral for 14 days, interferon Beta 1-b 8MIU SC every other day for 3 doses.

$4 \mathrm{~h}$ later he developed metabolic acidosis as he developed DKA that was appropriately managed.

We kept him on mechanical ventilation for 5 days, he was stable, afebrile, maintained normal $\mathrm{O}_{2}$ Sat, and normal vital data. With regular laboratory follow-up, especially D-dimer and lymphocytes count (Figures 2 and 3) We kept imatinib on hold during days of intubation and mechanical ventilation.

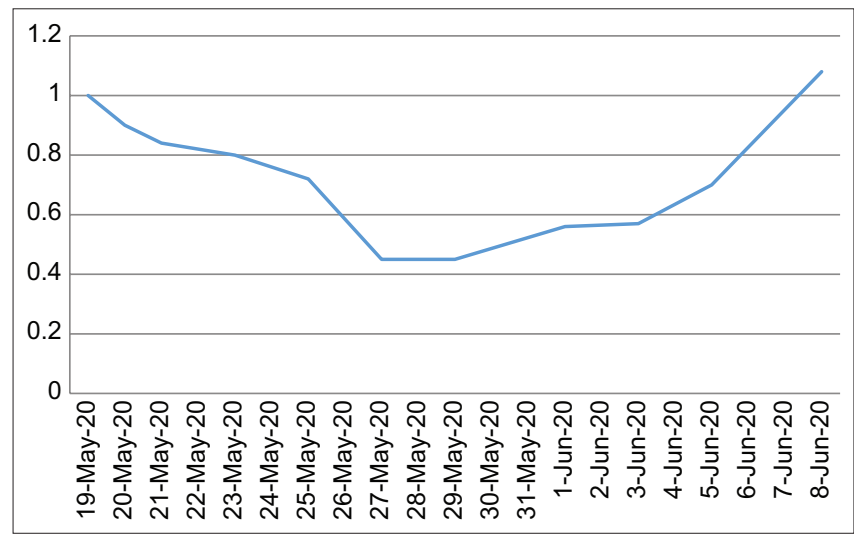

Figure 2: Lymphocytes count during course of the disease

After extubating him, as patient is clinically stable, we resumed imatinib. However, as patient is receiving ritonavir which has interaction with imatinib leading to increasing effect of imatinib, we reduced dose of imatinib by 50\%, $200 \mathrm{mg}$ OD till he finished antiviral therapy.

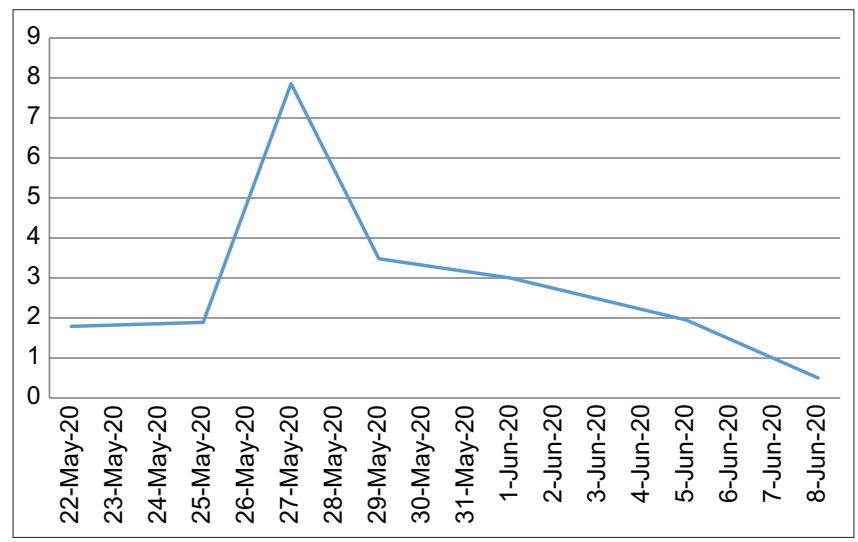

Figure 3: D-dimer level during course of the disease

Patient finished 14 days of antiviral, his PCR for COVID 19 come negative twice, we resumed imatinib $400 \mathrm{mg}$ daily and discharged patient on prophylactic dose of enoxaparin $6000 \mathrm{IU}$ for 45 days, we could not start direct oral anticoagulant due to its interaction with imatinib as both potentiate toxicity of each other. Twenty 
days later Q-PCR for BCR-ABL is repeated and confirm patient still in MMR.

\section{Discussion}

SARS-CoV-2 is a zoonotic beta-coronavirus, similar to Middle East respiratory syndrome (MERS) and SARS-CoV-1, which causes a respiratory illness known as COVID-19. Most cases have mild symptoms, for example, fever, exhaustion, and dry cough [1]. Notwithstanding, a few cases are serious and may be confounded by ARDS prompting mechanical ventilation. The infection could be serious and complications are frequently found among patients with comorbidities, such as hypertension and respiratory and cardiovascular system diseases [2].

Some studies have suggested that cancer patients are more vulnerable to infection with SARSCoV-2 than healthy people and have a worse prognosis because their immune systems are suppressed by the effects of the tumors and anti-cancer treatment [3]. However, this view is controversial [4].

$\mathrm{CML}$ is a neoplastic disease of hematopoietic stem cells that have an annual incidence of 0.4 $1.75 / 100,00011-15$, the therapeutic landscape of chronic myeloid leukemia (CML) has significantly changed over the previous year. Most patients with chronic phase (CP) now have a normal life expectancy. Our goal is achieving a stable deep molecular response (DMR) and discontinuing medication for treatment-free remission (TFR). TKIs have improved patient outcomes to near-normal, and thereby survival. Imatinib was the first generation TKI that showed higher rates of cytogenetic and molecular responses [5].

There is no proof that hematological neoplasms, for example, CML, regardless of whether they are on TKIs, may put the patient at high hazard for COVID-19 and its complications [6].

In one study done in Wuhan, they studied SARS-CoV-2 infections in CML patients according to their response to anti-CML therapy, and found that just 1 of $299(0.3 \%)$ patients with an optimal response was diagnosed with COVID-19. Of the 50 patients who failed to respond to CML treatment or had a poor response, 1 patient $(2 \%)$ had a clinical diagnosis of COVID19. Thus, patients who failed to achieved an optimal response to CML therapy appear more likely to have a symptomatic infection with SARS-CoV-2 [7]. This may be explained by; an optimal response to TKI treatment may be associated with immune recovery. CML patients exhibit selective depletion of effector T-reg cells [8], [9], while TKIs increase the number of natural killer cells (NK), NK-LGL, and T-LGLs cells [10], which play a role in regulating immunity. Moreover, the previous studies have reported that imatinib and other TKI drugs have antiviral activity in vitro against MERS-COV and SARSCOV [11], although the risk of infection in patients with CML on dasatinib is debatable [6].

Table 1: Laboratory test results on the day of admission

\begin{tabular}{lll}
\hline Laboratory test & Value & Normal range \\
\hline White blood cell & $8.18 \times 10^{6} / \mu \mathrm{L}$ & $4-10$ \\
Absolute neutrophil count & $6.34 \times 10^{6} / \mu \mathrm{L}$ & $2-7$ \\
Lymphocytes count & $1 \times 10^{6} / \mu \mathrm{L}$ & $1.5-3$ \\
Hemoglobin & $13.9 \mathrm{~g} / \mathrm{dL}$ & $13-17$ \\
Platelet & $240 \times 10^{9} / \mathrm{L}$ & $150-400$ \\
Ferritin & $1594 \mathrm{ng} / \mathrm{mL}$ & $22-322$ \\
LDH & $419 \mathrm{U} / \mathrm{L}$ & $125-135$ \\
D-dimer & $1.79 \mathrm{mg} / \mathrm{L}$ & $0.00-0.49$ \\
\hline LDH: Lactate dehydrogenase. & &
\end{tabular}

In case presented here, our patient had optimal response to imatinib, so we did not stop imatinib during course of the disease based on the previous data but after intubation and mechanical ventilation, his prognosis was dismal, and we do not have enough data about continuation of CML therapy at that time, so we hold it.

\section{Table 2: Laboratory tests on date of ICU admission}

\begin{tabular}{lll}
\hline Laboratory test & Value & Normal range \\
\hline WBC & $6 \times 10^{6} / \mu \mathrm{L}$ & $4-10$ \\
Absolute neutrophil count & $4.57 \times 10^{6} / \mu \mathrm{L}$ & $2-7$ \\
Lymphocytes count & $0.45 \times 10^{6} / \mathrm{LL}$ & $1.5-3$ \\
Hemoglobin & $12.5 \mathrm{~g} / \mathrm{dL}$ & $13-17$ \\
Platelet & $454 \times 10^{9} / \mathrm{L}$ & $150-400$ \\
Ferritin & $1650 \mathrm{ng} / \mathrm{mL}$ & $22-322$ \\
LDH & $600 \mathrm{UL}$ & $125-135$ \\
D-dimer & $7.9 \mathrm{mg} / \mathrm{L}$ & $0.00-0.49$ \\
\hline LDH: Lactate dehydrogenase. & &
\end{tabular}

There is a variable risk of infectious complications with targeted therapy. According to Reinwald et al., kinase inhibitors that target the mTOR, Janus kinase and BCR pathways exhibit an increased risk of infection, sometimes fatal complications; while this risk is minor with kinase inhibitors of the angiogenesis-related growth factors [12].

Interestingly, analysis of virus-host interaction retrieved available anti-cancer target therapy that can potentially act against the SARS-CoV-2, among these drugs, a TKI (afatinib) and a proteasome inhibitor (ixazomib) [13]. Furthermore, the previous studies have highlighted the use of kinase inhibitors in the reduction of virus infectivity and this led some researchers to investigate the role of anti-tyrosine kinase such as sunitinib and erlotinib in the treatment of COVID-19 [14].

Our patient responded as all other patient with profound lymphopenia and high D-dimer when he developed sever COVID 19 pneumonia and ARDS.

Lymphopenia is the most common laboratory finding. However, leukocytosis and leukopenia have been reported [15]. Lymphocyte count and lymphopenia may serve as a rapid tool that can quickly identify COVID19 patients with more severe clinical presentation, viral infection may either directly suppress bone marrow or induce an immune-mediated destruction of lymphocytes resulting in Iymphopenia [16], [17]. Thrombocytopenia is more common in patients with critical diseases, and it could also distinguish between mild and severe 
cases [18]. Some patients might develop cytokine storm or secondary hemophagocytic Iymphohistiocytosis, which is characterized mainly by cytopenias and hyperferritinemia plus the other features [19].

Infection with the novel coronavirus SARSCoV-2 has been associated with inflammation and a hypercoagulable state, with increases in fibrin, fibrin degradation products, fibrinogen, and D-dimers and it associated worse clinical outcomes [20]. There is a potential role for coagulopathy in COVID-19. Although the exact mechanism may remain controversial, it is not typical of disseminated intravascular coagulopathy of the kind seen in septicemia [21].

Heparin has been implicated in binding to COVID-19 spike proteins as well as down-regulating interleukin-6 (IL-6) [22], which has been shown to be elevated in COVID-19 patients, and thus unfractioned heparin or $\mathrm{LMWH}$ remains as the best choice of anticoagulant for those patients. It is possible that these patients may even require continued anticoagulation for a certain period of time following hospital discharge [21] and we followed this statement in our patient.

Finally, good responders to TKIs in CML are less likely to develop symptoms of SARS-CoV-2 than non-responders [7]. Hence, clinicians are encouraged not to withhold targeted therapy for good responders rather than pursuing it where not indicated; and this principle is also true irrespective of the pandemic.

\section{Conclusion}

In the presence of non-severe confirmed SARSCoV-2, interruption of TKI treatment is not necessary. In case of severe SARS-CoV-2, TKI interruption should be discussed on a case-to case basis.

\section{Statement of Ethics}

The case was approved by the ethical committee of our center and the patient signed a written informed consent to publish the case (including publication of images).

\section{Availability of Data and Materials}

The datasets during and/or analyzed during the current case available from the corresponding author on reasonable request.

\section{Acknowledgment}

We acknowledge the ICU Department.

\section{Author Contributions}

All authors equally contributed in witting and editing.

\section{References}

1. Wu Z, McGoogan JM. Characteristics of and important lessons from the coronavirus disease 2019 (COVID-19) outbreak in China: Summary of a report of 72,314 cases from the Chinese Center for Disease Control and Prevention. JAMA. 2020;323(13):1239-42. https://doi.org/10.1001/jama.2020.2648 PMid:32091533

2. Yang J, Zheng Y, Gou X, Pu K, Chen Z, Guo Q, et al. Prevalence of comorbidities in the novel Wuhan coronavirus (COVID-19) infection: A systematic review and meta-analysis. Int J Infect Dis. 2020;94:91-5.

PMid:32173574

3. Liang W, Guan W, Chen R, Wang W, Li J, Xu K, et al. Cancer patients in SARS-CoV-2 infection: A nationwide analysis in China. Lancet Oncol. 2020;21(3):335-7.

PMid:32066541

4. Wang $\mathrm{H}$, Zhang L. Risk of COVID-19 for patients with cancer. Lancet Oncol. 2020;21:e181.

PMid:32142621

5. Hochhaus A, Baccarani M, Silver RT, Schiffer C Apperley JF, Cervantes F, et al. European leukemia net 2020 recommendations for treating chronic myeloid leukemia. Leukemia. 2020;34(4):966-84.

PMid:32127639

6. Alshurafa A, Alkhatib M, Abou Kamar M, Yassin MA. Confirmed coronavirus disease-19 (COVID-19) in a male with chronic myeloid leukemia complicated by febrile neutropenia and acute respiratory distress syndrome. Case Rep Oncol. 2020;13(2):569-77. https://doi.org/10.1159/000508378

7. Wang D, Guo J, Yang Z, You Y, Chen Z, Chen S, et al. The first report of the prevalence of COVID-19 in chronic myelogenous leukemia patients in the core epidemic area of China: A multicentre. Cross Sectional Surv. Hematol. 2020;1:20034876.

8. Tanaka A, Nishikawa H, Noguchi S, Sugiyama D, Morikawa $H$, Takeuchi $\mathrm{Y}$, et al. Tyrosine kinase inhibitor imatinib augments tumor immunity by depleting effector regulatory $\mathrm{T}$ cells. J Exp Med. 2020;217(2):e20191009.

PMid:31704808

9. Ureshino $\mathrm{H}$, Shindo T, Kimura S. Role of cancer immunology in chronic myelogenous leukemia. Leuk Res. 2020;88:106273. PMid:31765938

10. Climent N, Plana M. Immunomodulatory activity of tyrosine kinase inhibitors to elicit cytotoxicity against cancer and viral infection. Front Pharmacol. 2019;10:1232.

PMid:31680987 
11. Coleman CM, Sisk JM, Mingo RM, Nelson EA, White JM, Frieman MB. Abelson kinase inhibitors are potent inhibitors of severe acute respiratory syndrome coronavirus and Middle East respiratory syndrome coronavirus fusion. J Virol. 2016;90(19):8924-33. https://doi.org/10.3389/fphar.2019.01232 PMid:27466418

12. Reinwald M, Boch T, Hofmann WK, Buchheidt D. Risk of infectious complications in hemato-oncological patients treated with kinase inhibitors. Biomark Insights. 2015;10(Suppl 3):55-68. https://doi.org/10.1128/jvi.01429-16 PMid:27127405

13. AvchaciovK, Burmistrova O, Fedichev PO. Al for the Repurposing of Approved or Investigational Drugs Against COVID. Available from: https://www.researchgate.net/publication/339998830 Al_for_the_repurposing_of_approved_or_investigational. [Last accessed on2020 Mar 15].

14. Stebbing J, Phelan A, Griffin I, Tucker C, Oechsle O, Smith D. COVID-19: Combining antiviral and anti-inflammatory treatments. Lancet Infect Dis. 2020;20(4):400-2. https://doi. org/10.1016/j.lfs.2020.117627 PMid:32113509

15. Chen N, Zhou M, Dong X, Qu J, Gong F, Han $\mathrm{Y}$, et al. Epidemiological and clinical characteristics of 99 cases of 2019 novel coronavirus pneumonia in Wuhan, China: A descriptive study. Lancet. 2020;395(10223):507-13. https://doi.org/10.1016/ s1473-3099(20)30132-8 PMid:32007143

16. Zheng M, Gao Y, Wang G, Song G, Liu S, Sun D, et al. Functional exhaustion of antiviral lymphocytes in COVID-19 patients. Cell Mol Immunol. 2020;17(5):533-5. https://doi.org/10.1016/ s0140-6736(20)30211-7

PMid:32203188

17. Sarzi-Puttini $P$, Giorgi $V$, Sirotti $S$, Marotto $D$, Ardizzone $S$, Rizzardini G, et al. COVID-19, cytokines and immunosuppression: What can we learn from severe acute respiratory syndrome? Clin Exp Rheumatol. 2020;38(2):337-42. PMid:32202240

18. Lippi G, Plebani M, Henry BM. Thrombocytopenia is associated with severe coronavirus disease 2019 (COVID-19) infections: A meta-analysis. Clin Chim Acta. 2020;506:145-8.

PMid:32178975

19. Mehta P, McAuley DF, Brown M, Sanchez E, Tattersall RS, Manson JJ. COVID-19: consider cytokine storm syndromes and immunosuppression. Lancet. 2020;395(10229):1033-4. https:// doi.org/10.1016/j.cca.2020.03.022 PMid:32192578

20. Guan WJ, Ni ZY, Hu Y, Liang WH, Ou CQ, He JX, et al. Clinical characteristics of coronavirus disease 2019 in China. N Engl J Med. 2020;382:1708-20. https://doi.org/10.1016/ s0140-6736(20)30628-0

21. Atallah B, Mallah SI, AIMahmeed W. Anticoagulation in COVID19. Eur Heart J Cardiovasc Pharmacother. 2020;6(4):260-1. PMid:32352517

22. Mummery RS, Rider CC. Characterization of the heparinbinding properties of IL-6. J Immunol. 2000;165(10):5671-569.

PMid:11067924 